\title{
Beyond the cocoon: Some plain talk about careers
}

\author{
Richard Hamilton CM MD FRCPC
}

\begin{abstract}
A ter many years spent in the protected, rather cocoon-like environment of a postgraduate training program, medical residents and fellows can find the prospect of emergence into the real working world somewhat daunting. This is a transition that is best anticipated and planned, recognizing that the life and the responsibilities of a consultant or an academic physician differ from those of a trainee.

Recent surveys suggest that not all medical practitioners are content with their professional lives these days (1). Approximately one-half express a significant level of job dissatisfaction, the percentage for women exceeding that for men. Some recent trends may contribute to this unhappiness. For example, modern communications and significant advances in health care have helped to foster unrealistic public expectations about our ability to diagnose and cure all. At the same time, Internet access has exposed most patients to comprehensive information on all manner of illnesses; this knowledge is helpful at times but, when taken out of context, can create confusion and complicate doctor-patient relationships. Also, chronic underfunding of the health care system has had an impact on working conditions, in large part due to a serious shortage of qualified specialists in Canada. The modern emphasis on evidence-based medicine has come about for good reasons but the decreased use of old-fashioned clinical assessment of the individual patient interferes with the doctor's capacity to administer "whole" patient care. Furthermore, health research has become increasingly sophisticated and specialized, leaving little or no room for the amateur, no matter how gifted. In the background of all these trends, there is the welcome increase in prevalence of women in medicine and the need to continue to address issues associated with this demographic shift. In one way or another, all of the above trends have generated some dissatisfaction and anxiety among medical practitioners but, in almost every instance, their benefits have greatly exceeded their negative effects.

So, is it a more difficult working world for the Canadian medical specialist than it used to be? On balance, I don't think so, but there are potential pitfalls out there and it is advisable to anticipate and prepare for them. Here I am projecting beyond specialty exams and selection of a career niche, both of which are important mileposts in any career. I do not wish to minimize their importance, but there is excessive focus on the

specialty exam now as the consummation rather than the beginning of a career. Selection of a niche within a specialty is a complex issue on which to generalize, but most training programs, through mentors who play key roles in this regard, deal effectively with this aspect of career development. I intend to focus on the steps that fellows and residents must take to minimize the long-term risk of professional dissatisfaction and burnout, while maximizing contentment. Taking the lead from a prominent late night television host, I offer my list of the 10 best strategies for finding and retaining satisfaction and fulfillment in a career as a medical specialist. These suggestions, which were made to Canadian fellows in Gastroenterology at a recent national meeting, probably apply to most specialty trainees.

\section{Strategy \#10}

Work hard to develop strong consultant skills; they differ significantly from those required of a fellow or resident. If you have not already done so, begin now to think and act as if the "buck" stops with you. As a consultant you will be expected to provide clear, decisive advice on diagnostic and management strategies. It is not just about good case presentations at rounds. Also, for your sake, the patient's sake and the referring doctor's sake, it is very important to communicate well with the referring doctor and with the patient. The sooner that you apply these principles to your clinical training, and they do need to be learned, the better a consultant you will become.

\section{Strategy \#9}

If you intend to establish yourself in research, you will face challenges as an independent investigator beyond those you encounter as a fellow or resident. You will become responsible for generating the funds and facilities to support your research, and the capacity to generate research funds will depend on your productivity. Make no mistake: that means peer-reviewed publications and, to a lesser extent, abstracts accepted at major meetings. In your initial years as a faculty member, undertake at least one project that you know you can complete and publish within an appropriate period of time, to demonstrate to your peers that you can be productive as an independent investigator. If it is a collaborative project, make sure that you pick collaborators who will deliver on their commitments.
\end{abstract}

This article was abstracted by the author from his presentation of the Annual Ivan Beck Lecture to Fellows and Residents in Gastroenterology at the

Canadian Digestive Disease Week in Banff, Alberta, February 2004

Montreal Children's Hospital, Montreal, Quebec

Correspondence: Dr Richard Hamilton, Montreal Children's Hospital, 2300 Tupper Street, Montreal, Quebec H3H 1 P3.

Telephone 514-412-4400 ext 22712, fax 514-412-4478, e-mail carolyn.mandel@muhc.mcgill.ca

Received for publication April 5, 2004 Accepted June 30, 2004 


\section{Strategy \#8}

In the years to come, it is difficult for me to envisage a professional life for you that does not involve teaching in addition to learning. Great teachers are made, not born. All the good ones prepare themselves carefully, even though it might appear that they are performing "off the cuff". You will never have a better time than now to practice and develop your teaching skills and, over the years, there will be no activity more fulfilling.

\section{Strategy \#7}

To reduce the risk of burnout, try to position yourself so that you are in demand. Burnout can result from a feeling of being trapped in a role or job from which there seems to be no escape. The best protection for you will come from gaining skills and achievements in clinical practice or in the academic sphere that make you a marketable commodity. I am not counselling revolution but there is something very comforting about knowing that, if conditions become untenable, you will have the opportunity to move on.

\section{Strategy \#6}

Recognize that your learning curve must not plateau once you complete your specialty exams or PhD studies - actually it should accelerate thereafter. You can and should learn far more during your staff years than you did as a resident or fellow. Early in a research career, it is particularly important that you function within a critical mass of scientists, because it is from these interactions that you will learn the most. The ability to capitalize on these opportunities usually requires a deliberately proactive, open-to-criticism, nondefensive attitude on your part. That is more difficult than you may realize but the effort will be worth it.

\section{Strategy \#5}

I suggest that major administrative responsibilities be left for relatively late in your career unless you decide that this will be your primary focus, in which case you will need additional training in administration. Your early years in any position are very important and I think it's best not to clutter them with extensive administrative responsibilities, too many committees or generally unproductive time commitments. Accept your fair share but learn to say no. Because of the high prevalence of many diseases in the developing world, involvement in international health might be an attractive option for some of you, but it is preferable to establish yourself at home before taking on the rest of the world.

\section{Strategy \#4}

There are two skills that may not have been emphasized in your training but they will be very important to you in the years to come. The first is the ability to manage your time efficiently - the discipline of presenting the relevant features of a case concisely, of adhering to a schedule and of avoiding endlessly circuitous discussions. In short, learn to make your time count. I suggest that, at the end of the day, you assess what you have achieved, and that you consciously explore strategies to improve your productivity, distinguishing between crucial activities and those that were of peripheral importance or a waste of time! It helps to avoid procrastination. Those who fail to address this area have problems coping with the real world, no matter how talented they might be.

\section{Strategy \#3}

The second important skill is the ability to write in a clear, concise manner. For most of us, good writing is a learned skill that comes from practice combined with some guidance. The sooner you practice your writing and acquire that guidance the better. You should be working on a paper now, with the help of a mentor, to gain practical experience, and be prepared to keep at it until you get it right. This painful trial-and-error process will pay off. These days, the general level of writing skills among medical graduates is rather low. This is a significant handicap, particularly for those who end up working in academic centres.

\section{Strategy \#2}

Don't ignore your life beyond medicine and work hard to enhance it. Not only does a well-rounded life make you and those close to you more content, it makes you a more productive professional. Try not to lose your friends or your sense of humour. It's a huge help to find a partner who understands and supports your career goals.

\section{Strategy \#1}

Remember that success in your professional and personal life will be largely dependent on your capacity to deal with people. Dr Jean Gray, in a talk delivered to a Canadian Society for Clinical Investigation Symposium, eloquently presented this point of view, with which I strongly agree (2). She pointed out that those with whom you work will all have strengths and weaknesses and it behooves you to maximize their strengths. If you establish a reputation as a good person with whom to work, good people will want to work with you. If you surround yourself with excellent people, encourage them to do "their thing", and recognize their contributions. They will greatly enhance your own productivity and your pleasure. It's very dangerous to become hung up on your own status, and it's very advantageous to respect your colleagues at all levels and to delegate effectively.

In closing, I want you to realize that you have chosen a great profession with plenty of unsolved problems requiring your intelligence and energy. You will face a vast array of opportunities and challenges for which I'm sure you will be ready. I wish you long, fulfilling and contented careers.

\section{REFERENCES}

1. Physician Health in Canada: Current Status and Recommendations for Action. Canadian Medical Association, 2002.

2. Gray J. A life in academe. Clin Invest Med 1999;22:275-7. 


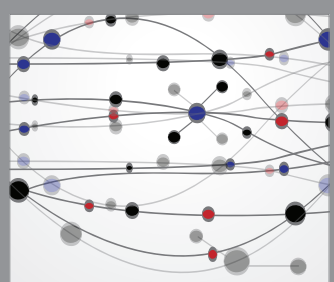

The Scientific World Journal
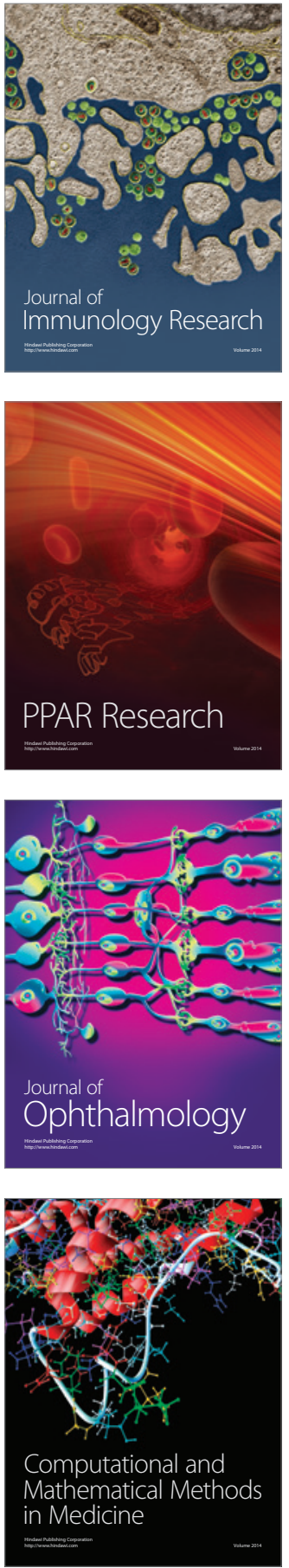

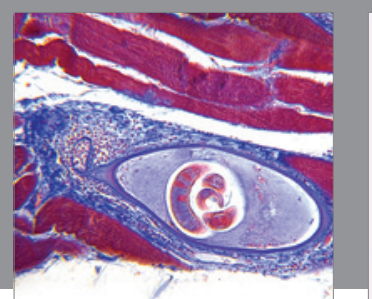

Gastroenterology Research and Practice

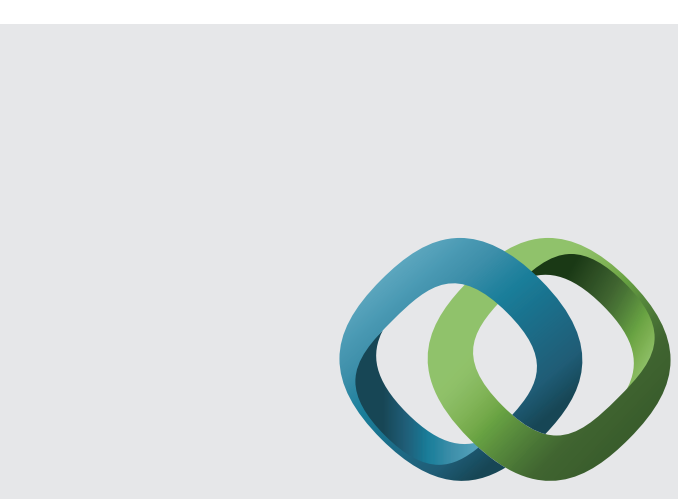

\section{Hindawi}

Submit your manuscripts at

http://www.hindawi.com
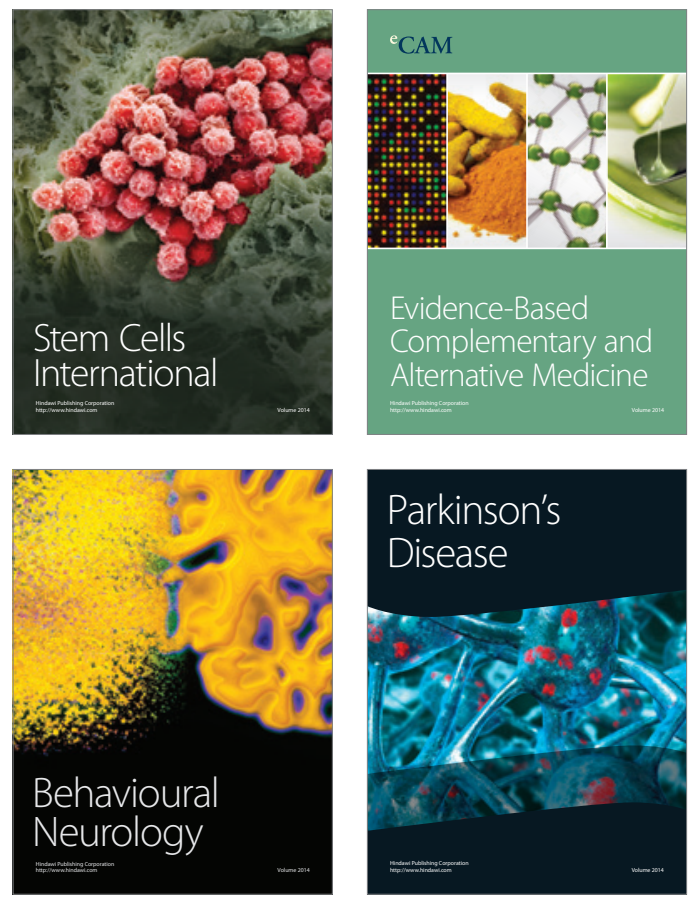
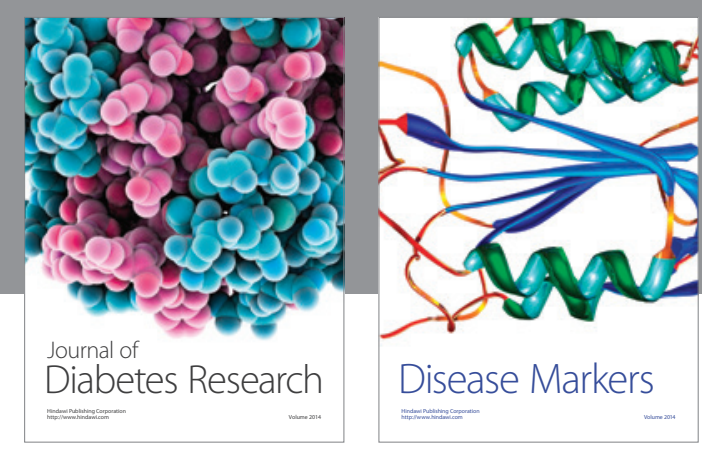

Disease Markers
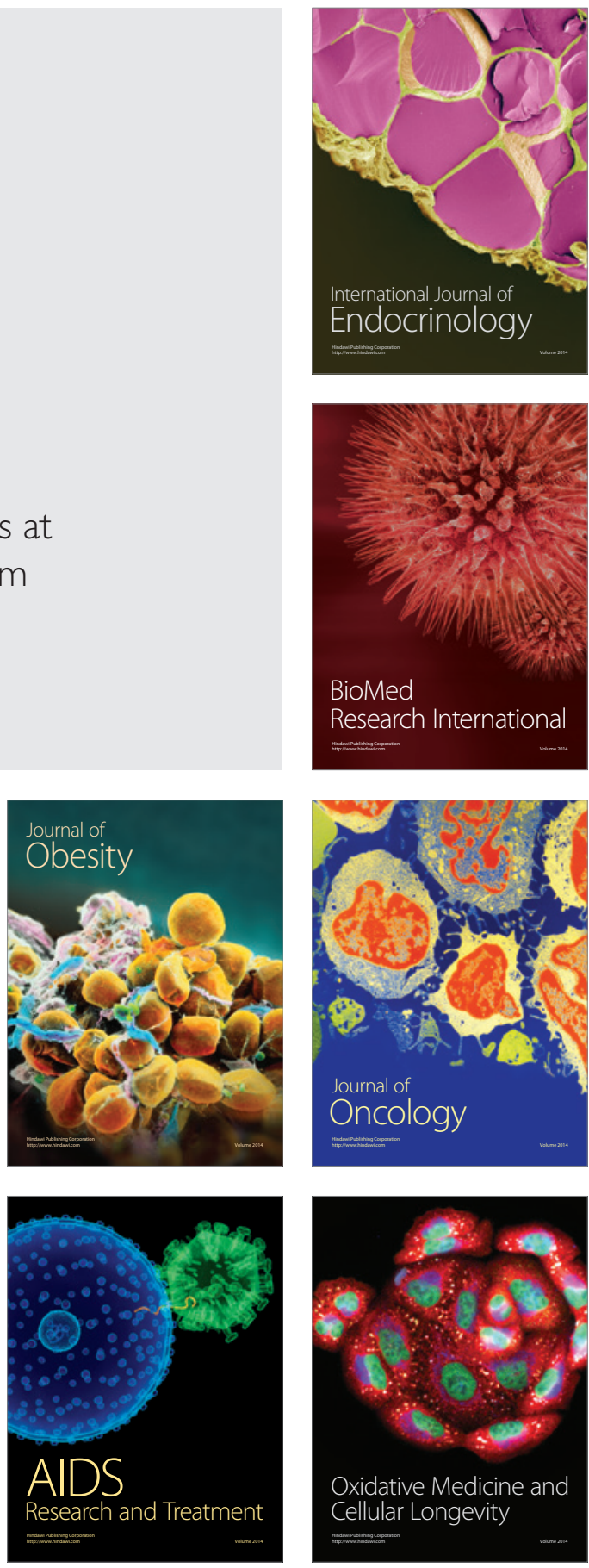